\title{
In order to be medically correct, we must be politically correct in class
}

\section{Claire Junga Kim}

Department of Medical Education, Ewha Womans University School of Medicine, Seoul, Korea

Last year, I was delighted by the surprising news that our students established a new club (dong-ari) to study feminism. Even though I was fascinated by this news, I realized that I was ignorant of this new educational need until now. In fact, I kept thinking that feminism and inclusiveness are very important in our lives, but sadly, is mostly rejected as premature by the Korean medical community. However, inspired by our students, I reflected on my own medical education. Surprisingly, I became aware of a clear need for inclusiveness and "political correctness" in medical education. Students have courageously started to point out faculty members' politically incorrect remarks. Furthermore, they view the issue not just with resentment but also from an academic perspective; more and more students are familiar with feminist studies, thanks to their liberal pre-medical education, and gender equality education during elementary and secondary school. They seek greater gender sensitivity in society, including the medical community [1]. Indeed, the entire Korean society is now dealing with the \#MeToo movement. Although all politically incorrect remarks amount to sexual harassment, increased gender sensitivity on the part of students and the general public requires faculty members to critically reflect on their behavior.

These circumstances raise the questions: "Are we, the medical community and educators of that community, well prepared for the future? Can we remain trustworthy? What should we do, what should we teach and what should we fix?" We are at a critical point in medical education, where we need to reinforce trust among students, patients, their families, and medical care providers. These objectives can be achieved by addressing the new educational need for political correctness. In this article, I will posit that medical education should be critically examined and reformed in order to achieve political correctness. This aim is consistent with the fundamental goal of the medical profession to be trustworthy and to create "the healing relationship [2]." In other words, in order to stay medically correct, we should be politically correct. Of course, this starts in class.

Korean J Med Educ 2018 Sep; 30(3): 257-260.

https://doi.org/10.3946/kjme.2018.100

eISSN: 2005-7288

(C) The Korean Society of Medical Education. All rights reserved. This is an open-access article distributed under the terms of the Creative Commons Attribution Non-Commercial License (http:// creativecommons.org/licenses/by-nc/3.0/), which permits unrestricted non-commercial use, distribution, and reproduction in any medium, provided the original work is properly cited. 
Political correctness may be defined as "the avoidance of forms of expression or action that are perceived to exclude, marginalize, or insult groups of people who are socially disadvantaged or discriminated against [3]." What politically incorrect events, behaviors, or language are found in medical education? To name a few examples: describing homosexuality explicitly or implicitly as a disease; ridiculing sexual identity; belittling female medical professionals and patients; stereotyping based on sex; dismissing certain groups of people as "impolite" without an effort to understand their conflict with behavioral norms in clinical settings; and ignoring the existence of relationships other than heterosexual gender-conforming couple. These problems are aggravated by the fact that there is no discussion during medical education of the unique characteristics of any social minority, and by the absence of a policy prohibiting any form of discrimination, including hate speech.

It should be so obvious as to not require repeating that political correctness is necessary in a society where every individual has equal rights. Inspired by students' awareness, I attempt to show why political correctness is necessary in medical education; it is because political correctness in medical education is the precondition for medical correctness.

First, as professionals who took the oath to care for the sick and not to harm them, we should pay attention to whether medical care is provided to those in need and at the same time does not cause unjustifiable harm. Politically incorrect medical education betrays this ideal since it leads to discriminatory medical service. When medical professionals define something that is not a disease as a disease, or consider certain groups of people inferior to others, the affected people cannot achieve the levels of health that they would have achieved otherwise. In fact, access to health care is determined not only by the ability to pay; it can also be influenced by what values medicine explicitly/implicitly advocates. For example, doctors who believe lesbian, gay, bisexual, transgender, and queer (LGBTQ) identity is a disease cannot provide valid medical care to these patient groups; consequently, both medical care utilization and the health of LGBTQ people suffer. This limitation is also observed in case of LGBTQ medical professionals: the heterosexual male-centered subculture of medicine [4] may marginalize and hinder them from functioning to their full potential. This not only constitutes an unhealthy environment for such medical professionals, but also fails to create an inclusive medical practice for patients. This failure is caused by LGBTQ patients feeling that they are not welcome by medical professionals, just as LGBTQ professionals themselves are prevented from expressing their own values and identities in their medical practice and cannot assure their patients of equal care. Thus, if one seriously considers the harm that medicine may cause, one inevitably concludes that political incorrectness in medicine leads to medical incorrectness. Due to the normative power that medicine and medical professionals enjoy, medical professionals may cause harm when they treat patients. Although the discussion of "do no harm" in Korea has largely been focused on physical harms such as pain during futile treatments, the harm that medical professionals may cause includes psychological harm such as stigmatization. We classify patients as normal and pathological, and sub-categorize the latter category for understanding and treatment purposes. These activities in medicine may accompany the harms that I alluded to, but can be justified by the fact that we make those classifications and categorizations for the treatment of patients and there is a reasonable prospect for successful treatment. In other words, abuse of the normative power of medicine without such justification 
cannot be accepted. For example, pathologizing specific conditions such as sexual orientation cannot be justified because the resulting stigmatization cannot be justified for the treatment purposes. Our mission as medical teachers is to teach students to understand the dual nature of our power and to further the ideals of the Hippocratic Oath.

Second, we should be politically correct in order to avoid medical incorrectness because political incorrectness may produce scientifically skewed knowledge. Contrary to the belief in the absolute objectiveness of science, it is a well-known fact that science has a value-driven bias. This bias applies to medical science as well [5]. For example, Martin [6] has pointed out how stereotyped male-female roles have influenced "science." When scientists' views are biased as a result of the social structure, their questions, research methods, and conclusions are so distorted that they cannot capture the scientific truth. In addition to stereotyping, assuming that a certain group of people doesn't even exist is also detrimental to medical science. Because such assumptions hinder research of that group, we lack sufficient knowledge of what that group needs in order to achieve physical, mental, and social well-being [7]. These all prevent us from being medically correct since they blind us.

Needless to say, medical faculty members play a crucial role in determining the culture of schools and hospitals. If we as medical faculty members practice political correctness, we can change our culture and bring about medically correct research, practice, and delivery of healthcare. Furthermore, since this is of paramount importance, professional bodies and academic associations must provide systematic policy-level leadership and recommendations. The Korean Society of Medical Education, of course, should assume this responsibility.
In terms of medical education, three activities are crucial: open discussion of the issue, integration into education, and declaration of policy. First, we should start open discussion on political correctness in medical education and share the results. Occasionally, the emphasis on political correctness results in total silence on the subject. There is a tendency to avoid sensitive subjects, such as the differences between men and women or the gender-nonconforming population. However, as noted, when we avoid discussing something, it becomes as if it does not even exist and any valuable knowledge or service the discussion may provide becomes unattainable. Therefore, we need a forum for open discussion on the issue of political correctness in medical education. In this regard, students can play a pivotal role in the discussion. Their keen perception is a valuable resource.

Second, a course that integrates political correctness into medical education is needed. Medical students are already asking for education on diversity and gender equality [1]. This demand is clear evidence suggesting a new educational need [8]. Increased public awareness on this issue also shows the critical need for a systematic approach to teaching and learning political correctness in order to remain trustworthy professionals.

Last, but not the least, a policy-level approach by academic associations and professional bodies is needed. In various ways, such as publishing recommendations or reports, or commenting on public issues, academic associations or professional bodies can reconfirm to their members and the public their mission as a healing profession. Being politically correct is an undeniable need in today's medical education. Enhanced awareness on the part of public and students deserves respect from doctors and educators. And this is crucially related to the ideals of medical professionals. Again, being politically correct is not just about maintaining a polite discourse- 
it is also about being medically correct.

ORCID:

Claire Junga Kim: https://orcid.org/0000-0001-6889-5478

Acknowledgements: None.

Funding: None.

Conflicts of interest: No potential conflict of interest relevant to this article was reported.

Author Contributions: Whole process, ranging from conception of the work to critical revision, was done by the author.

\section{References}

1. Desirable pre-med curriculum. Student presentation on self-learning fare: team leadership project meeting; December 3, 2017; Seoul, Korea.

2. Pellegrino ED, Thomasma DC. The virtues in medical practice. New York, USA: Oxford University Press; 1993.
3. English Oxford Living Dictionaries. Definition of political correctness in English. Web Site. https://en. oxforddictionaries.com/definition/political_correctness. Accessed March 28, 2018.

4. Cheng LF, Yang HC. Learning about gender on campus: an analysis of the hidden curriculum for medical students. Med Educ. 2015;49(3):321-331.

5. Dijkstra AF, Verdonk P, Lagro-Janssen AL. Gender bias in medical textbooks: examples from coronary heart disease, depression, alcohol abuse and pharmacology. Med Educ. 2008;42(10):1021-1028.

6. Martin E. The egg and the sperm: How science has constructed a romance based on stereotypical malefemale roles. Signs J Women Cult Soc. 1991;16(3): 485-501

7. World Health Organization. Constitution of WHO: principles. Web Site. http://www.who.int/about/mission/ en/. Accessed March 28, 2018.

8. Dent JA, Harden RM, Hodges BD. A practical guide for medical teachers. 4th ed. London, UK: Elsevier; 2013. 